\title{
Hubungan Usia dan Obesitas dengan Infertilitas pada pasien di Rumah Sakit Kepresidenan RSPAD Gatot Soebroto
}

\section{The relationship between Age and Obesity with Infertility in Gatot Soebroto Army Presidential Hospital}

\author{
Ayuningtyas Tri Handini ${ }^{1}$, Mirfat $^{2}$ \\ ${ }^{1}$ Faculty of Medicine, YARSI University, Jakarta \\ ${ }^{2}$ Department of Biology, Faculty of Medicine, Universitas YARSI, Jakarta \\ Correspondence Email: mirfat@yarsi.ac.id
}

\begin{abstract}
Abstrak
Infertilitas adalah kondisi setelah setahun menikah dengan hubungan seksual yang tidak terlindungi, tetapi tetap tidak bisa hamil. Menurut sensus ada 12\%, atau sekitar 3 juta pasangan tidak subur tersebar di seluruh Indonesia. Ada beberapa faktor risiko yang dapat menyebabkan infertilitas, seperti usia dan obesitas. Penelitian ini bertujuan untuk mengetahui hubungan antara usia dan obesitas dengan infertilitas di RS Kepresidenan Gatot Soebroto. Penelitian ini merupakan penelitian analitik dengan desain cross-sectional. Sampel yang digunakan adalah 50 wanita terdiri dari 25 pasien infertil dan 25 pasien tidak subur. Data diambil dari rekam medis pasien di klinik infertilitas, Rumah Sakit Kepresidenan Gatot Soebroto dari April 2015 hingga Maret 2016. Variabel yang digunakan adalah usia dan obesitas. Hasil bivariat menunjukkan bahwa tidak ada korelasi yang signifikan antara usia dan infertilitas $(p=0,572)$ serta faktor obesitas yang tidak signifikan terkait dengan infertilitas $(p=0,235)$. Berdasarkan hasil penelitian dengan tingkat kepercayaan $95 \%$ dapat disimpulkan bahwa semua variabel yang diteliti dalam penelitian ini tidak berhubungan signifikan dengan infertilitas namun kelebihan berat badan menjadi faktor yang perlu diperhatikan karena variasi etnis yang menyebabkan kelebihan berat badan cukup untuk meningkatkan risiko gangguan metabolisme pada penduduk Asia Selatan.
\end{abstract}

Kata kunci: infertilitas, usia, obesitas

\begin{abstract}
Infertility is a condition after a year of marriage with unprotected sexual intercourse, but still not being able to get pregnant. According to the census there were $12 \%$, or about 3 million infertile couples scattered throughout Indonesia. There are a several risk factors that can cause infertility, such as age and obesity This study aimed to determine the relationship between age and obesity with infertility in Gatot Soebroto Army Presidential Hospital. This research was an analytic study with a cross-sectional design. The sample used were 50 women consists of 25 infertile patients and 25 not infertile patients. Data was taken using medical records of patients in infertility clinic, Gatot Soebroto Army Presidential
\end{abstract}


Hospital from April 2015 until March 2016. The variables used were age and obesity. Bivariate results indicate that there was no significant correlation between age and infertility $(p=0.572)$ as well as obesity factor that was not significantly associated with infertility $(p=0.235)$. Based on the research results with a 95\% confidence level can be concluded that all the variables that examined in this study were not significantly associated with infertility. But overweight becomes a factor that need to be considered because of the ethnic variations that causing overweight is enough to increase the risk of metabolic disorders in South Asian population.

Keywords: Infertility, age, obesity

\section{Pendahuluan}

Infertilitas merupakan salah satu dari masalah penting yang sering dialami pasangan suami istri. Menurut Syafrudin dan Hamidah (2009) infertilitas adalah setelah setahun berumah tangga dengan persetubuhan yang tidak memakai pelindung, tetapi belum terjadi kehamilan.

Berdasarkan penelitian secara global yang dilakukan oleh Mascarenhas et al (2012) pada tahun 2010, perempuan usia 20-44 tahun yang memiliki risiko kehamilan, 1,9\% tidak dapat sampai melahirkan bayi hidup (infertilitas primer). Dari wanita yang telah melahirkan setidaknya satu kali dan memiliki risiko kehamilan, 10,5\% tidak dapat memiliki anak lagi (infertilitas sekunder).

Di Indonesia menurut sensus penduduk terdapat $12 \%$ atau sekitar 3 juta pasangan infertil yang tersebar di seluruh Indonesia. Diperkirakan muncul sekitar 2 juta pasangan infertil baru setiap tahun dan jumlah ini terus meningkat (Fauziyah, 2012).

Resiko terjadinya infertilitas dpat meningkat karena beberapa faktor, salah satunya adalah faktor usia. Menurut Krishna (2013) kesuburan seorang wanita akan menurun drastis setelah mereka menginjak usia 35 tahun. Sedangkan pada pria, mereka mempunyai risiko yang lebih tinggi mendapatkan masalah infertilitas saat berumur 40 tahun ke atas. Selain itu faktor obesitas juga berpengaruh terhadap infertilitas. Penelitian yang dilakukan oleh Simanjuntak (2014) menunjukkan bahwa ibu pasangan usia subur yang obesitas mempunyai peluang 3,102 kali untuk mengalami infertilitas dibandingkan dengan ibu pasangan usia subur yang tidak obesitas.

\section{Bahan dan Metoda Penelitian}

Penelitian ini merupakan penelitian analitik dengan disain Cross Sectional. Populasi dalam penelitian ini adalah seluruh pasien yang memeriksakan diri di poliklinik infertilitas, Departemen Obstetri dan Ginekologi, RS Kepresidenan RSPAD Gatot Soebroto pada periode April 2015 - Maret 2016. Sampel yang digunakan berjumlah 50 orang yang terdiri dari 25 pasien infertil dan 25 pasien tidak infertil.

Data diambil dengan menggunakan rekam medis pasien di poliklinik infertilitas RS Kepresidenan RSPAD Gatot Soebroto dengan kriteria inklusi pasien perempuan yang tercantum dalam rekam medis periode April 2015 - Maret 2016 dan rekam medis harus diisi dengan lengkap dan memenuhi semua variabel yang diteliti. Analisis data dilakukan secara komputerisasi dengan perangkat lunak SPSS versi 16.0 menggunakan uji Fisher dan 
Kolmogorov Smirnov dengan pendekatan univariat dan bivariat.

\section{Hasil Penelitian}

Pasien yang berkunjung ke poliklinik infertilitas RS Kepresidenan RSPAD Gatot Soebroto mayoritas berusia 25-29 tahun (36\%). Pada tabel 1 dapat dilihat bahwa dari 50 responden terdapat 3 orang yang mengalami obesitas (6\%). Hasil univariat karakteristik subjek penelitian di RS Kepresidenan RSPAD Gatot Soebroto Periode April 2015 - Maret 2016 memperlihatkan bahwa sebanyak $36 \%$ pasien yang datang berada pada rentang usia 25-29 tahun, dengan usia paling tua adalah 45 tahun dan yang paling muda ialah 23 tahun.

Pada penelitian ini digunakan 50 responden yang terdiri dari 25 pasien infertil dan 25 pasien tidak infertil. Pasien yang obesitas hanya ditemukan pada pasien infertil sebanyak 3 orang (6\%). Dua orang berasal dari rentang usia 30-34 tahun, satu orang berasal dari rentang usia 35-39 tahun. Mayoritas pasien memiliki berat badan normal yakni sebanyak 31 orang $(62 \%)$, kemudian berat badan berlebih sebanyak 12 orang (24\%) dan kekurangan berat badan sebanyak 4 orang (8\%).
Tabel 2 menunjukkan gambaran usia pasien di RS Kepresidenan RSPAD Gatot Soebroto pada periode April 2015 - Maret 2016. Pasien infertil ditemukan paling banyak berada pada rentang usia 30-34 tahun (40\%) sedangkan jumlah paling sedikit berada pada rentang usia 20-24 tahun (4\%) dan usia 45-49 tahun (4\%). Pasien tidak infertil paling banyak ditemukan pada rentang usia 25-29 tahun (40\%).

Pada pasien infertil terdapat 10 dari 25 orang (40\%) yang berusia 30-34 tahun (Tabel 4). Selain itu, hasil penelitian memperlihatkan bahwa terdapat $12 \%$ atau 3 dari 25 orang pasien infertil yang mengalami obesitas (Tabel 3).

Pada penelitian ini tidak ditemukan adanya hubungan yang signifikan antara usia dan infertilitas (Tabel 4). Hal ini didasarkan pada uji Kolmogorov Smirnov yang menghasilkan $p$ value sebesar 0,572, nilai alpha > 0,05 yang berarti tidak ada perbedaan proporsi antara usia pasien infertil dan tidak infertil. Pada penelitian ini tidak ditemukan adanya hubungan yang signifikan antara obesitas dan infertilitas. Hal ini terlihat dari hasil Fisher's Exact Test yakni $p$ value sebesar 0,235 jauh lebih besar dari 0,05 (Tabel 5).

Tabel 1. Karakteristik Subjek Penelitian di RS Kepresidenan RSPAD Gatot Soebroto Periode April 2015 - Maret 2016

\begin{tabular}{|c|c|c|c|}
\hline No. & Variabel & Jumlah (n) & Persentase (\%) \\
\hline \multirow[t]{3}{*}{1.} & Infertilitas & & \\
\hline & Infertil & 25 & 50 \\
\hline & Tidak Infertil & 25 & 50 \\
\hline \multirow[t]{7}{*}{2.} & Usia & & \\
\hline & $20-24$ & 3 & 6 \\
\hline & $25-29$ & 18 & 36 \\
\hline & $30-34$ & 16 & 32 \\
\hline & $35-39$ & 7 & 14 \\
\hline & $40-44$ & 4 & 8 \\
\hline & $45-49$ & 2 & 4 \\
\hline \multirow[t]{3}{*}{3.} & Obesitas & & \\
\hline & Obesitas & 3 & 6 \\
\hline & Tidak Obesitas & 47 & 94 \\
\hline
\end{tabular}

Total 50 
Tabel 2. Gambaran Usia pasien di Poliklinik Infertilitas RS Kepresidenan RSPAD Gatot Soebroto Periode April 2015 - Maret 2016

\begin{tabular}{ccccccc}
\hline \multirow{2}{*}{ Usia } & \multicolumn{2}{c}{ Infertil } & \multicolumn{3}{c}{ Tidak Infertil } & \multicolumn{2}{c}{ Total } \\
\cline { 2 - 7 } & $(\mathbf{n})$ & $(\%)$ & $(\mathbf{n})$ & $(\%)$ & $(\mathbf{n})$ & $(\%)$ \\
\hline $\mathbf{2 0 - 2 4}$ & 1 & 4 & 2 & 8 & 3 & 6 \\
$\mathbf{2 5 - 2 9}$ & 8 & 32 & 10 & 40 & 18 & 36 \\
$\mathbf{3 0 - 3 4}$ & 10 & 40 & 6 & 24 & 16 & 32 \\
$\mathbf{3 5 - 3 9}$ & 2 & 8 & 5 & 20 & 7 & 14 \\
$\mathbf{4 0 - 4 4}$ & 3 & 12 & 1 & 4 & 4 & 8 \\
$\mathbf{4 5 - 4 9}$ & 1 & 4 & 1 & 4 & 2 & 4 \\
\hline Total & $\mathbf{2 5}$ & $\mathbf{1 0 0}$ & $\mathbf{2 5}$ & $\mathbf{1 0 0}$ & $\mathbf{5 0}$ & $\mathbf{1 0 0}$
\end{tabular}

Tabel 3. Gambaran Status Obesitas Pasien di Poliklinik Infertilitas RS Kepresidenan RSPAD Gatot Soebroto Periode April 2015 - Maret 2016

\begin{tabular}{lccccccc}
\hline \multirow{2}{*}{ Obesitas } & \multicolumn{2}{c}{ Infertil } & \multicolumn{2}{c}{ Tidak Infertil } & \multicolumn{2}{c}{ Total } \\
\cline { 2 - 9 } & $(\mathbf{n})$ & $(\%)$ & $(\mathbf{n})$ & $(\%)$ & $(\mathbf{n})$ & $(\%)$ \\
\hline Obesitas & 3 & 12 & 0 & 0 & 3 & 6 \\
Tidak Obesitas & 22 & 88 & 25 & 100 & 47 & 94 \\
\hline Total & $\mathbf{2 5}$ & $\mathbf{1 0 0}$ & $\mathbf{2 5}$ & $\mathbf{1 0 0}$ & $\mathbf{5 0}$ & $\mathbf{1 0 0}$ &
\end{tabular}

Tabel 4. Hubungan Usia terhadap Infertilitas di RS Kepresidenan RSPAD Gatot Soebroto Periode April 2015 - Maret 2016

\begin{tabular}{cccc}
\hline \multirow{2}{*}{ Usia } & \multicolumn{2}{c}{ Status Infertilitas } & P Value \\
\cline { 2 - 3 } & Infertil & Tidak Infertil & \\
\hline $\mathbf{2 0 - 2 4}$ & 1 & 2 & \\
$\mathbf{2 5 - 2 9}$ & 8 & 10 & \\
$\mathbf{3 0 - 3 4}$ & 10 & 6 & 0,572 \\
$\mathbf{3 5 - 3 9}$ & 2 & 5 & \\
$\mathbf{4 0 - 4 4}$ & 3 & 1 & \\
$\mathbf{4 5 - 4 9}$ & 1 & 1 & \\
\hline Total & $\mathbf{2 5}$ & $\mathbf{2 5}$ &
\end{tabular}

Tabel 5. Hubungan Obesitas terhadap Infertilitas di RS Kepresidenan RSPAD Gatot Soebroto Periode April 2015 - Maret 2016

\begin{tabular}{lccc}
\hline \multicolumn{1}{c}{ Status } & \multicolumn{2}{c}{ Status Infertilitas } & P Value \\
\cline { 2 - 3 } \multicolumn{1}{c}{ Obesitas } & Infertil & Tidak Infertil & \\
\hline Obesitas & 3 & 0 & \multirow{2}{*}{0,235} \\
Tidak Obesitas & 22 & 25 & \\
\hline Total & 25 & 25 &
\end{tabular}




\section{Diskusi}

Pasien yang datang merupakan wanita yang sudah menikah, sehingga kendala-kendala seperti gangguan reproduksi yang dapat menyebabkan pasien sulit hamil akan segera di konsultasikan ke dokter. Hal ini sesuai dengan pernyataan Depkes (2015) bahwa usia ideal seorang wanita untuk menikah ialah saat dewasa muda yakni berkisar 25-35 tahun karena usia tersebut dinilai sudah cukup siap dari aspek kesehatan, mental emosional, pendidikan, sosial ekonomi dan reproduksi. Dag dan Dilbaz (2015) mengatakan bahwa prevalensi obesitas dan kelebihan berat badan sedang mengalami peningkatan dan telah menjadi epidemi di seluruh dunia. Obesitas memiliki pengaruh yang merugikan pada semua sistem, termasuk kesehatan reproduksi. Wanita dengan berat badan berlebih dan obesitas memiliki insiden yang lebih tinggi dalam mengalami gangguan menstruasi dan anovulasi.

Populasi obesitas tertinggi di dunia adalah Amerika Serikat yakni sebesar 26\% dan terendah ialah Asia Tenggara yakni sebesar 3\% (WHO, 2017). Sedangkan di Indonesia penderita obesitas mencapai 11 juta penduduk atau $6,8 \%$ dari populasi dewasa (Latif, 2014). WHO (2017) juga mengatakan bahwa di semua wilayah WHO perempuan cenderung lebih berisiko mengalami obesitas daripada laki-laki. Di daerah Afrika, Timur Tengah dan Asia Tenggara, perempuan memiliki kira-kira dua kali lipat prevalensi obesitas dibandingkan dengan laki-laki.

Pada penelitian yang dilakukan oleh Ticoalu (2012) tentang prevalensi obesitas pada mahasiswa universitas Sam Ratulangi angkatan 2011 dengan usia responden berkisar antara 1620 tahun didapatkan 5 orang perempuan $(2,6 \%)$ yang mengalami obesitas. Sedangkan pada penelitian ini didapatkan $6 \%$ responden yang mengalami obesitas dengan rata-rata umur 31,7 tahun. Hal ini sesuai dengan pendapat Waluyo dan Putra (2010) bahwa semakin bertambah usia, metabolisme tubuh mulai berubah hingga berat badan mudah meningkat, tetapi sulit untuk turun. Kesuburan wanita menurun secara alamiah sejak usia 35 tahun karena cadangan sel telur semakin sedikit (Purwoastuti dan Walyani, 2015). Namun di luar itu masih banyak sekali faktor yang dapat memengaruhi kesuburan seorang wanita. Faktor stres dan gizi yang kurang atau malah berlebih dapat memengaruhi sekresi hormon seseorang sehingga dapat mengganggu siklus menstruasi dan ovulasi. Kelainan-kelainan seperti endometriosis, miom, sumbatan pada tuba juga kerap menjadi hambatan kesuburan seseorang. Oleh karena itu pada usia di bawah 35 tahunpun seorang wanita sudah rentan terhadap infertilitas. Hal ini sesuai dengan yang dikatakan Boivin et al (2009) bahwa dari 3583 wanita dan dari 14 penelitian yang telah dilakukan, umur wanita yang paling banyak mengalami infertilitas ialah pada rentang usia 29,7-36,8 tahun. Menurut Barbieri (2010), dengan meningkatnya usia, semakin sulit pula untuk mendapatkan anak. Usia 20-24 tahun fertilitas wanita mencapai $100 \%$ sedangkan pada usia 30-34 tahun fertilitas wanita turun menjadi $85 \%$.

Selain usia, obesitas juga diketahui sebagai salah satu faktor yang berhubungan dengan infertilitas. Menurut Witjaksono (2015), obesitas diketahui menjadi salah satu faktor risiko terjadinya infertilitas karena obesitas dapat memacu terjadinya resistensi insulin dimana tubuh tidak mampu mengelola glukosa secara cepat. Resistensi insulin menyebabkan peningkatan kadar insulin darah (hiperinsulinemia) sehingga semakin tinggi 
insulin semakin besar hambatan perkembangan foliker (sel telur) dalam ovarium.

Tidak ditemukannya hubungan antara usia dengan infertilitas mungkin dikarenakan adanya faktor lain diluar variabel yang diteliti, seperti faktor stres, lingkungan, pola hidup atau penyebab organik seperti gangguan ovulasi, kelainan tuba yang dapat timbul kapan saja tanpa dipengaruhi oleh usia penderita. American Society for Reproductive Medicine (2016) juga mengemukakan bahwa $25 \%$ dari pasangan infertil memiliki lebih dari satu faktor yang dapat memengaruhi infertilitasnya. Hal ini tentu saja akan berimbas pada hasil penelitian. Hal ini sesuai dengan penelitian Diatri dkk (2014) di Klinik Bersalin Insan Medika Semarang yang mengatakan bahwa variabel usia tidak berhubungan.

Tidak ada hubungan yang bermakna secara statistik bukan berarti tidak bermakna secara klinis. Pada pasien infertil di penelitian ini ditemukan 7 orang (28\%) yang mengalami kelebihan berat badan. Hal sesuai dengan yang dikatakan Watson (2015) bahwa pada masa reproduksi wanita, kelebihan berat badan dan obesitas dapat dikaitkan dengan infertilitas anovulasi maupun infertilitas ovulasi. Diperkirakan terdapat 25\% dari infertilitas anovulasi di Amerika Serikat dikarenakan oleh kelebihan berat badan. Resiko relatif anovulasi meningkat 1,3 kali pada wanita dengan IMT 24$31 \mathrm{~kg} / \mathrm{m}^{2}$ dan 2,7 kali pada wanita dengan IMT $>32 \mathrm{~kg} / \mathrm{m}^{2}$ dibandingkan dengan wanita dengan berat badan normal.

Kemungkinan infertilitas pada pasien di RS Kepresidenan RSPAD Gatot Soebroto Periode April 2015 - Maret 2016 terkait dengan infertilitas anovulasi yang disebabkan oleh kelebihan berat badan. Pendapat ini didukung oleh Balen (2014) yang mengatakan bahwa ada variasi etnik yang penting pada kejadian resistensi insulin. IMT $>30 \mathrm{~kg} / \mathrm{m}^{2}$ biasanya meningkatkan risiko resistensi insulin pada ras Kaukasian, sementara pada penduduk Asia Selatan IMT >25 kg/m² sudah cukup untuk meningkatkan risiko gangguan metabolik. Chan dan Woo (2010) juga mengatakan bahwa sebuah meta-analisis antara kelompok-kelompok etnis yang berbeda juga menunjukkan bahwa persentase lemak tubuh 3-5\% lebih tinggi pada populasi Asia dibandingkan dengan populasi Kaukasia untuk IMT yang sama, dan IMT 3-4 unit lebih rendah pada populasi Asia dibandingkan dengan populasi Kaukasia dengan persentase lemak tubuh yang sama.

\section{Simpulan}

Usia dan obesitas tidak berhubungan secara signifikan dengan infertilitas, namun kelebihan berat badan menjadi faktor yang patut dipertimbangkan karena adanya variasi etnik yang menyebabkan kelebihan berat badan dapat meningkatkan resiko gangguan metabolik.

\section{Daftar Pusataka}

American Society for Reproductive Medicine. 2016. Stats and Facts. https://www.asrm.org/ detail.aspx?id=2322. Diakses pada tanggal 5 Februari 2017.

Balen AH. 2014. Obesity and Reproduction, dalam Infertility in Practice. Edisi ke 4, hal 50. CRC Press, London.

Barbieri RL. 2010. Female Infertility, dalam Reproductive Endocrinology. Edisi ke 7, hal. 512. Elsevier, Philadelphia.

Boivin L, Bunting L, Collins JA, dan Nygren KG. 2009. International Estimates of Infertility Prevalence and Treatment Seeking: Potential Need and Demand for Infertility 
Medical Care. Hum Reprod 24: 23792380 .

Chan RSM dan Woo J. 2010. Prevention of Overweight and Obesity: How Effective is the Current Public Health Approach. Int. J. Environ. Res. Public Health 7:765-783.

Dag Z dan Dilbaz B. 2015. Impact of Obesity on Infertility in Women. J Turk Ger Gynecol Assoc 16:111-7.

Depkes. $2015 . \quad$ http://www.depkes. go.id/resources/download/pusdatin/infodati n/ infodatin\% 20reproduksi\%20remajaed.pdf. Diakses pada tanggal 3 Desember 2016.

Diatri D, Irsam M, Novitasari. 2014. Hubungan Antara Usia, Siklus Haid dan Infeksi Organ Reproduksi Wanita terhadap Kejadian Infertil pada Wanita di Klinik Bersalin Insan Medika Semarang. http://digilib.unimus.ac.id/files/disk1/159/jtp tunimus-gdl-devitadiat-7939-1-abstrak.pdf. Diakses pada tanggal 11 Desember 2016.

Fauziyah Y. 2012. Infertilitas dan Gangguan Alat Reproduksi Wanita, hal 2. Nuha Medika, Yogyakarta.

Krishna A. 2013. Infertilitas, dalam Mengenali Keluhan Anda, hal 77-78. Informasi Medika, Jakarta.

Latif S. 2014. Indonesia Masuk 10 Negara Terbanyak Dihuni Orang Tambun. http://www.dream.co.id/dinar/indonesiamasuk-10-negara-terbanyak-dihu ni-oranggemuk-141201h. html. Diakses pada tanggal 10 Februari 2017.

Mascarenhans MN, Flaxman SR, Boerma T, Vanderpoel S, Stevens GA. 2012. National, Regional, and Global Trends in Infertility Prevalence Since 1990: A Systematic Analysis of 277 Health Surveys. Plos Medicine 9(12): e1001356
Purwoastuti E dan Walyani ES. 2015. Masalah Infertilitas dan Penanganannya, dalam Panduan Materi Kesehatan Reproduksi dan Keluarga Berencana, hal 211. PustakaBaruPress, Yogyakarta.

Simanjuntak LS. 2015. Hubungan Obesitas dengan Infertilitas pada Ibu Pasangan Usia Subur di Desa Wonosari Tanjung Morawa tahun 2014. http://repository.usu.ac.id/handle/1234567 89/54484. Diakses pada tanggal 4 Desember 2016.

Syafrudin dan Hamidah. 2009. Infertilitas, dalam Kebidanan Komunitas, hal 40-43. EGC, Jakarta.

Ticoalu ESHR. 2012. Prevalensi Obesitas pada Mahasiswa Fakultas Kedokteran Universitas Sam Ratulangi Angkatan 2011. Suplemen 4(3): 142-152.

Waluyo S dan Putra BM. 2010. The Book of Anti Aging: Rahasia Awet Muda. Edisi ke 1, hal.5. Alex Media Computindo, Jakarta.

Watson RR. 2015. Handbook of Fertility: Nutrition, Diet, Lifestyle and Reproductive Health. Edisi 1, hal. 123. Elsevier, San Diego.

WHO. $2017 . \quad$ Obesity. http:// www.who.int/gho/ncd/risk_factors/obesity_ text/en/. Diakses pada tanggal 10 Februari.

Witjaksono J. 2015. Ingin Hamil - PCOS: Obesitas Masalah, Peranan dan Cara Penganggulangan pada Wanita PCOS. https://juliantowitjaksono.com/2015/10/15/i ngin-hamil-pcos-obesitas-masalahperanan-dan-cara-penanggulangan-padawanita-pcos/. Diakses pada tanggal 11 Desember 2016. 